\title{
O Julgamento da ADPF n. 54: uma reflexão à luz de Ronald Dworkin
}

\author{
Maria Eugenia Bunchaft ${ }^{1}$
}

Resumo: A Arguição de Descumprimento de Preceito Fundamental n. 54 foi ajuizada pela Confederação Nacional dos Trabalhadores na Saúde no STF que, por oito votos a dois, julgou procedente o pedido, declarando a inconstitucionalidade da interpretação segundo a qual a interrupção da gravidez de feto anencéfalo seria tipificada no Código Penal. Defendendo uma leitura moral do ordenamento jurídico, Dworkin sustenta que a interpretação de princípios substantivos deve considerar, não apenas a Constituição como um todo, mas também a história, as tradições e as práticas constitucionais. Nesse sentido, pretende-se articular a temática da ADPF n. 54 à perspectiva substancialista delineada por Dworkin, cuja proposta de leitura moral pode ser um referencial teórico importante para compreender formas de judicialização voltadas para a proteção de direitos de gestantes de fetos anencéfalos. Pretende-se demonstrar que, no julgamento da ADPF no 54, o STF conseguiu justificar de forma coerente os conceitos que integram o domínio do valor, articulando-os de uma maneira que um complemente o sentido do outro, inexistindo conflito.

Palavras-chave: Anencefalia. STF. Dworkin.

\begin{abstract}
The Allegation of Unconstitutionality number 54 was filed in the Brazilian Supreme Court by the National Confederation of Health Workers, and the Supreme Court, by eight votes to two, upheld the application, declaring the unconstitutionality of the interpretation that the interruption of pregnancy of anencephalic fetus would be typified in the Criminal Code. Advocating a moral reading of the law, Dworkin argues that the interpretation of substantive principles should consider not only the Constitution as a whole, but also the history, traditions and constitutional practices. Therefore, we intend to articulate the theme of the Allegation of Unconstitutionality number 54 with the Dworkin's substantialist perspective, whose proposal for a moral reading can be an important theoretical framework for understanding forms of judicialization aimed at protecting the rights of women with pregnancy of an anencephalic fetus. We intend to demonstrate that, in the judgment of the Allegation of Unconstitutionality number 54, the Brazilian Supreme Court was able to consistently justify the concepts that comprise the field of value, articulating them in a way that one direction complements the other, therefore eliminating the conflict.
\end{abstract}

Key words: Anencephaly. Brazilian Supreme Court. Dworkin.

1 Doutora e Mestre em Teoria do Estado e Direito Constitucional pela PUC-Rio. Professora e Pesquisadora do Departamento de Direito do Centro Universitário de Volta Redonda (UNIFOA).E-mail: mbunchaft@ig.com.br.

Recebido em: 07/05/2012.

Revisado em: 16/08/2012.

Aprovado em: 27/09/2012. 


\section{Introdução}

De início, é premente lecionar que um dos momentos mais relevantes da trajetória jurídico-institucional do STF foi o julgamento da Arguição de Descumprimento de Preceito Fundamental n 54, ajuizada pela Confederação Nacional dos Trabalhadores na Saúde (CNTS). O Plenário, por oito votos a dois, julgou procedente o pedido formulado na ADPF n. 54, para declarar a inconstitucionalidade da interpretação segundo a qual a interrupção da gravidez de feto anencéfalo seria conduta tipificada nos artigos 124, 126 e 128, incisos I e II do Código Penal, prevalecendo o voto do Min. Relator, Marco Aurélio Mello, vencidos os Ministros César Peluso e Ricardo Lewandowski.

Desse modo, a anencefalia caracteriza-se como uma má-formação congênita, ou seja, como uma anomalia que consiste na ausência de abóbada craniana, com ausência dos hemisférios cerebrais ou estes, se presentes, são representados por massas pequenas que repousam na base. Trata-se de uma alteração decorrente de falha no início do desenvolvimento embrionário e do mecanismo de fechamento do tubo neural. A Confederação Nacional dos Trabalhadores na Saúde afirma em nota prévia serem distintas as situações de antecipação terapêutica e a do aborto, tendo em vista que este último pressupõe potencialidade de vida extrauterina do feto. Resgata princípios constitucionais relativos à dignidade da pessoa humana, da legalidade, da liberdade e da autonomia da vontade, bem como o do direito à saúde.

Outrossim, adotando uma perspectiva eminentemente substancialista, Dworkin sustenta que a interpretação racionalmente construída a partir de princípios substantivos deve considerar, não apenas a Constituição como um todo, mas também a história, as tradições e as práticas constitucionais. Sob essa ótica, no julgamento da ADPF n. 54, o Plenário do STF partiu de uma leitura moral do ordenamento jurídico e de uma perspectiva reconstrutiva que, superando autocompreensões assimétricas de mundo, resguardou a independência ética de mulheres e consagrou de forma normativamente sensível o ideal de integridade, tão caro a Dworkin. 
Nesse sentido, pretende-se articular a temática da ADPF n. 54 para a perspectiva substancialista delineada por Dworkin, cuja proposta de leitura moral pode ser um referencial teórico importante para compreender formas de judicialização voltadas para a proteção de direitos de gestantes de fetos anencéfalos. Mas, por qual motivo se faz imprescindível para a compreensão da teoria do valor delineada por Dworkin na análise da temática da anencefalia? É necessária, porque a temática da anencefalia enseja um debate sobre a concepção de justiça, dignidade da pessoa humana, democracia, igualdade e liberdade na sua argumentação, que são conceitos interpretativos pertencentes ao domínio do valor.

No ensejo, um dos assuntos mais polêmicos envolvido no pronunciamento dos Ministros foi o voto divergente do Ministro Ricardo Lewandowski sobre os limites de atuação do STF; que deveria restringir sua atuação ao papel de legislador negativo, extirpando do ordenamento jurídico as normas constitucionais, e não como legislador positivo, criando uma nova causa de exclusão da ilicitude que não foi prevista pelo Código Penal. A principal crítica decorre do caráter contramajoritário da jurisdição constitucional e sua inevitável liberdade interpretativa.

Nessa configuração filosófica, pretende-se investigar se tal crítica pode ser minimizada quando se consideram contextos fáticos nos quais a expansão da atuação judicial for, não apenas imprescindível para resguardar a independência ética de grupos minoritários estigmatizados, mas também para consagrar uma Interpretação conforme a Constituição juridicamente sensível à ideia de unificação e de harmonia entre os valores. Ideia esta defendida por Dworkin em Justice for Hedgehogs (2011). Nessa obra, Dworkin analisa a temática da oposição entre monismo e pluralismo de valores. Portanto, como afirma Berlin em seu livro, The Hedgehogs and the Fox: An Essay on Tolstoy's View of History, "[...] a raposa sabe muitas coisas, mas o porco-espinho sabe apenas uma e grandiosa coisa [...]", afirma o poeta grego Arquíloco. (BERLIN, 1993, p. 435)

Não obstante toda a perspicácia da raposa e a possibilidade de desenvolver estratégias variadas para capturar o ouriço, no fim, a raposa termina superada pela mesma artimanha de sempre: o ouriço transforma-se em uma bola com espinhos apontando para direções diversas, invia- 
bilizando o seu bote. Para Berlin, essa célebre passagem de Arquíloco pode ser resgatada para classificar escritores e pensadores como ouriços e outros como raposas. No seio da discussão dworkiniana sobre o ceticismo interno e externo, propugna-se investigar a relevância da estratégia de conciliação de valores em uma rede harmoniosa para a análise dos princípios jurídicos envolvidos na temática da ADPF n. 54. Pretende-se analisar se tal estratégia, defendida por Dworkin, supera efetivamente a argumentação utilizada pelo Min. Ricardo Lewandowski sobre o papel do STF como legislador negativo e a função da técnica de Interpretação conforme a Constituição.

Por fim, pretende-se conectar o voto do Min. Gilmar Mendes à ideia dworkiniana de responsabilidade, de acordo com a qual o Estado não pode utilizar seu aparato repressivo para impor concepções morais hegemônicas sobre o valor intrínseco da vida, devendo estimular que os cidadãos tratem de decisões relativas ao aborto como questões de importância moral. Sob esse prisma, passa-se à análise do papel da interpretação na teoria de Dworkin.

\section{O Papel da Interpretação na Teoria de Ronald Dworkin}

É mister sublinhar que a interpretação é fundamental para a teoria de Dworkin, assumindo especial relevância a sua analogia com o romance em cadeia. A analogia pressupõe que, no processo interpretativo, cada autor deve tentar criar o melhor romance possível como se fosse resultante da atuação de um único autor, e não, como produto de diversos autores. A atitude interpretativa deve tratar elementos como personagens, trama, tema gênero em um sentido de continuidade e não como um novo começo. Diante dessa estrutura conceitual, é clara a assertiva de Dworkin:

[...] Assim como um romancista em cadeia deve encontrar, se puder, alguma maneira coerente de ver um personagem e um tema, tal que um autor hipotético com o mesmo ponto de vista pudesse ter escrito, pelo menos, a parte principal do romance até o momento em que este lhe foi entregue, Hércules deve encontrar, se puder, alguma teoria coerente sobre os direitos legais à indenização por da- 
nos morais, tal que um dirigente político com a mesma teria pudesse ter chegado à maioria dos resultados que os precedentes relatam [...] (DWORKIN, 2003b, p. 288)

Nesse particular, a atitude interpretativa permite compreender as instituições sob a sob "sua melhor luz" e tratar as pessoas com igual consideração e respeito. Dworkin resgata a ideia da prática de cortesia para demonstrar o que significa uma atitude interpretativa. A cortesia é uma prática social da vida que também é objeto de interpretação. No passado, tal prática demandava que os homens se levantassem quando uma mulher chegasse ao ambiente para cumprimentá-los, que abrissem as portas para as mulheres, que retirassem o chapéu quando estivessem em um ambiente fechado. Os membros da sociedade aceitam essa regra sem questionar, havendo uma crítica para os comportamentos desviantes.

Dessa maneira, em um determinado momento, os indivíduos começam a fazer perguntas sobre essa prática e a indagar sobre qual o motivo para aderirem a ela. Com a emancipação das mulheres, tais práticas caíram em desuso, passando a ser interpretadas como sinal de sexismo e de tratamento condescendente para com as mulheres. A prática da cortesia permite afirmar que a interpretação da prática social se concretiza dentro de seu próprio âmbito e não fora dela. Em Império do Direito, Dworkin (2003b) divide o processo interpretativo em três etapas. Na primeira etapa, pré-interpretativa: “[...] são identificadas as regras e padrões que consideram fornecer o conteúdo experimental da prática" (DWORKIN, 2003b, p. 81). Deve haver um elevado nível de convergência nessa fase. Dworkin exemplifica a regra do reconhecimento do Hart como a descrição dessa etapa.

Nesse contexto, na etapa interpretativa, “[...] o intérprete se concentra numa justificativa geral para os principais elementos da prática identificada na etapa pré-interpretativa" (DWORKIN, 2003b, p. 81). O nível de convergência já não é o mesmo da fase pré-interpretativa, no entanto, será nessa fase, que se iniciará o processo de justificação da prática social. Nesse ponto, 
[...] a justificativa não precisa ajustar-se a todos os aspectos ou características da prática estabelecida, mas deve ajustar-se o suficiente para que o intérprete possa ver-se como alguém que interpreta essa prática, não como alguém que inventa uma nova prática. (DWORKIN, 2003b, p. 81)

Por fim, há uma etapa pós-interpretativa na qual "[...] ele ajuste sua ideia daquilo que a prática realmente requer para melhor servir à justificativa que ele aceita na etapa interpretativa." (DWORKIN, 2003b, p. 81)

Em suma, em Justice for Hedgehogs, Dworkin (2011) sublinha que, na esfera do conhecimento, existem dois domínios que não se confundem: o da ciência e do valor. Uma vez que a moralidade, o direito e a ética pertencem ao domínio do valor, é necessária uma metodologia diferenciada para a análise das respectivas esferas que se diferencie dos pressupostos da epistemologia científica. Nesse sentido, assume especial relevância a interpretação, por meio da qual integram-se os diversos valores. A metaética, por exemplo, discute o status lógico dos juízos de valor que as pessoas comuns emitem quando afirmam que a descriminalização da antecipação terapêutica de fetos anencéfalos é errada ou que a discriminação contra transexuais é iníqua.

Nesse cenário, os filósofos metaéticos pressupõem uma perspectiva descritiva e desengajada, não assumindo posição sobre a moralidade do aborto. Nas palavras de Dworkin (2010, p. 212), “[...] não se pode demonstrar que a análise filosófica dos conceitos políticos seja descritiva nos moldes da investigação científica das espécies naturais. A liberdade não tem DNA." E conclui:

Os conceitos de liberdade, democracia, etc. funcionam como conceitos interpretativos de valor. O significado descritivo não pode ser removido da força valorativa porque o primeiro depende do segundo desse modo particular. (DWORKIN, 2010, p. 212)

A análise filosófica de um valor é normativa, engajada e conceitual. ${ }^{2}$

2 Sob esse prisma, Dworkin pondera que: “[...] portanto, não podemos evitar, e devemos agora enfrentar a questão de saber como o valor dos valores integrados, inclusive os 
Com efeito, é necessário estabelecer uma diferenciação entre o domínio do valor e a investigação científica, pois os conceitos morais não têm a mesma estrutura que as estruturas físicas. Em A Justiça de Toga, Dworkin (2010) estabelece aspectos comuns aos conceitos naturais e aos valores, como, por exemplo, a ideia de que a existência dos valores independe dos sentimentos que os indivíduos têm em relação a eles e de que ambos possuem uma estrutura profunda. No entanto, os conceitos naturais caracterizam-se por uma estrutura física e o valor por uma estrutura normativa. $\mathrm{O}$ autor, em passagem elucidativa, menciona que:

[...] A estrutura profunda dos valores políticos não é física - é normativa. Porém, assim como um cientista pode ter por objetivo, como um tipo específico de projeto, revelar a natureza mesma de um tigre ou do ouro ao expor a estrutura fundamental dessas entidades, assim também um filósofo político pode pretender revelar a natureza mesma da liberdade ao expor sua essência normativa. [...] (DWORKIN, 2010, p. 217)

Em síntese, o que diferencia um cientista que pretende descrever a estrutura de uma partícula e o filósofo que analisa conceitos como dignidade, liberdade ou igualdade, é uma diferença de grau: "Não podemos sensatamente argumentar que a análise filosófica sobre o valor é conceitual, neutra e desengajada. Mas, podemos sensatamente afirmar que é normativa, engajada e conceitual.” (DWORKIN, 2010, p. 220). Por isso, há relevância e necessidade de uma investigação a respeito da metodologia estabelecida para a justificação dos julgamentos de valor. O entendimento da objetividade dos valores e da possibilidade de um processo interpretativo capaz de alcançar a verdade é fundamental para a compreensão da temática da anencefalia. E é possível estabelecer interpretações a respeito dos valores de maneira que tanto dignidade da pessoa humana, privacidade, saúde e integridade físico-psíquica estejam interligados, reforçando-se

valores políticos, podem ser identificados. [...] Se quisermos entender melhor os valores integrados não instrumentais da ética, devemos compreendê-los de modo holístico e interpretativo, cada um à luz dos demais, organizados não hierarquicamente, mas na forma de uma cúpula geodésica. [...]" (DWORKIN, 2010, p. 226-227) 
mutuamente. Se os valores possuem existência objetiva, a interpretação permite alcançar respostas corretas para as questões morais.

Nesse quadro teórico, a teoria do valor é fundamental no estabelecimento da argumentação moral. Em seu artigo, Casos Dificeis, que compõe a obra Levando os Direitos a Sério (2002), Dworkin defendeu um dos aspectos mais controversos de sua teoria: "a teoria da resposta correta", que, à revelia do autor, tornou-se a "teoria da única resposta correta", sendo esta atribuída ao filósofo. Desde a obra O Império do Direito (2003b), assim como em $A$ Justiça de Toga (2010), e, por fim, em seu artigo, Objective and Truth: You'd Better Believed it (1996), Dworkin estabeleceu críticas ao ceticismo, que foram aprofundadas em Justice for Hedgehogs (2011). Se os valores são objetivos, surge a questão: os princípios morais de fato existem? Se afirmativa a resposta, como é possível alcançá-los? Como garantir a objetividade moral em face do desacordo moral? A primeira questão, relativa ao problema da demonstração da existência de princípios morais, é respondida pelo ceticismo externo arquimediano de forma antagônica à perspectiva de Dworkin.

Nessa perspectiva, Dworkin se contrapõe ao ceticismo externo, que discute a moralidade de uma perspectiva externa, razão pela qual entende que a moralidade somente pode ser discutida dentro do seu próprio âmbito. $\mathrm{O}$ segundo aspecto diz respeito à metodologia específica para os julgamentos de valor com o objetivo de alcançar a verdade. Se a moralidade integra um domínio independente e os desafios propostos por ela não podem ser solucionados de fora de seu próprio domínio, a metodologia deve ser utilizada "de dentro para fora". A problemática decorrente do terceiro questionamento é respondida pelo ceticismo interno. Esse ceticismo confirma que o valor é objetivo, mas há uma dificuldade em alcançar a verdade nos julgamentos de valor, tendo em vista a incerteza e a indeterminação.

Disso se infere, acredita-se, que os céticos externos pretendem uma descrição neutra e descritiva a respeito de conceitos como legalidade, liberdade e igualdade, sem qualquer juízo sobre qual desses valores é o 
mais importante. ${ }^{3}$ Diante do exposto, depreende-se que Dworkin se contrapõe a tal postura neutra e desengajada, pois nenhuma proposição de segunda ordem pode desqualificar os argumentos de primeira ordem. $\mathrm{O}$ conceito objetivo de verdade apropriado para a ciência não é adequado para domínios como a moralidade. Mas o fato de a aplicação da epistemologia científica não ser adequada para o âmbito da moral não exclui a possibilidade de objetividade da moralidade, pois a concepção objetiva de verdade é estabelecida por meio de argumentos normativos substantivos. A suposição segundo a qual a moralidade pode ser objetiva apenas se crenças morais se sujeitarem às normas epistemológicas da ciência é falsa.

Sob esse aspecto, embora desde O Império do Direito (2003b), Dworkin já tivesse assinalado suas críticas ao ceticismo externo, o autor apenas encontrou um argumento definitivo em Justice for Hedgehogs (2011). Nessa obra, por meio de uma argumentação vinculada ao Princípio de Hume, demonstra-se que o ceticismo externo arquimediano é autodestrutivo. O princípio de Hume, nas palavras de Dworkin, revela-se como um axioma da metaética segundo o qual

[...] nenhuma série de proposições sobre como o mundo é, como uma questão de fato científico ou metafísico, pode fornecer um argumento de sucesso - sem algum julgamento de valor escondido em seus interstícios - para qualquer conclusão sobre o que deve ser aquele conjunto de proposições. (DWORKIN, 2011, p. 44)

3 Desde O Império do Direito, o filósofo já delineava os objetivos do ceticismo externo: “[...] O ceticismo exterior é uma teoria metafísica, e não uma posição interpretativa ou moral. O cético exterior não contesta nenhuma afirmação moral ou interpretativa específica. Ele não diz que é um equívoco, de certa maneira, pensar que Hamlet versa sobre a protelação ou que a cortesia é uma questão de respeito, ou que a escravidão é iníqua. Sua teoria é, na verdade, uma teoria em segundo grau sobre a posição ou a classificação filosóficas dessas afirmações. Ele insiste em que elas não são descrições que possam ser comprovadas ou testadas, como na física: nega que os valores estéticos ou morais possam ser parte daquilo que chama de fundamentos do universo. Seu ceticismo é exterior por não ser engajado: afirma deixar o verdadeiro procedimento da interpretação à margem de suas conclusões. $\mathrm{O}$ cético exterior tem suas próprias opiniões sobre Hamlet e a escravidão e pode apresentar as razões pelas quais prefere essas opiniões àquelas que rejeita. Insiste, apenas, em dizer que todas essas opiniões são projetadas na realidade e não descobertas nela. [...]" (DWORKIN, 2003b, p. 98) 
É premente ponderar que o Princípio de Hume prescreve que premissas não valorativas não podem inspirar uma conclusão valorativa. Por isso, Dworkin contrapõe-se ao ceticismo externo, que estabelece sua teoria com base em proposições metaéticas, de segunda ordem. O princípio de Hume permite estabelecer a distinção entre dois tipos de ceticismo: o ceticismo interno e externo. O ceticismo externo é arquimediano, desengajado da moralidade, baseando-se em proposições de segunda ordem; o ceticismo interno é engajado na dimensão moral, fundamentando-se em proposições substantivas de primeira-ordem. Dworkin parte do pressuposto de que o ceticismo externo desdobra-se em ceticismo de erro e de status. O ceticismo de erro sustenta que todas as alegações morais são falsas e, portanto, a moralidade é um empreendimento equivocado, tendo em vista a falsidade de todas as proposições de primeira ordem. $\mathrm{O}$ autor sublinha que:

[...] Os céticos do erro alegam que todos os julgamentos morais são falsos. Um cético do erro pode entender a concepção ordinária como supor que as entidades morais existem: que o universo contém não apenas quarks, mésons, e outras partículas físicas muito pequenas, mas também as partículas especiais que denominei de morons, cuja configuração pode tornar verdade que as pessoas não devem torturar bebês e que as invasões militares opcionais que procuram a mudança do regime são imorais. [...] É ceticismo externo porque tem em vista confiar somente na metafísica neutra do valor: confia somente na reivindicação metafísica de que não existe nenhuma partícula moral. [...] (DWORKIN, 2011, p. 32)

Outrossim, para o ceticismo externo de erro, não é possível estabelecer proposições morais que afirmem se determinadas condutas são moralmente exigíveis. Somente entidades sobrenaturais poderiam impor deveres morais, mas estas não existem. Dworkin estabelece algumas críticas a John Mackie, um dos principais autores representantes do ceticismo de erro, que parte da constatação do desacordo moral sobre questões importantes, como ação afirmativa, aborto, justiça social. Mackie (apud DWORKIN, 2011, p. 47) destaca que "[...] alegações morais positivas de- 
vem ser falsas, porque as pessoas discordam sobre quais delas são verdadeiras."

No entanto, argumenta Dworkin, o simples fato da existência de um desacordo moral não significa que todas as convicções morais sejam equivocadas. A popularidade de uma convicção moral não representa uma evidência da sua verdade. A diversidade "[...] é apenas uma questão de fato antropológico, ela não pode por si só demonstrar que todos os julgamentos morais positivos são falsos" (DWORKIN, 2011 p. 48). E conclui:

[...] contudo, pessoas, na sua diversidade, podem decidir o que é verdade, e isso é uma questão de justificação da convicção, não a melhor explicação sobre convergência ou divergência. (DWORKIN, 2011, p. 48)

Ademais, Mackie se contrapõe à ideia de que, quando as pessoas sustentam opiniões morais verdadeiras, elas seriam movidas por bens objetivos. Isso seria estranho para Mackie, porque ele supõe que o bem objetivo "[...] deveria ser buscado por aqueles que estão familiarizados com eles." (MACKIE apud DWORKIN, 2011, p. 48). Dworkin (2011, p. 48-49), todavia, alega que "[...] nenhuma opinião moral positiva é justificada a menos que a opinião tenha sido produzida pelo contato direto com alguma verdade moral - que é motivacional."

Por fim, o último argumento do ceticismo de erro é o de que, uma vez que julgamentos morais pressupõem razões categóricas, eles são todos falsos. Haveria uma conexão entre ter uma razão e ter um desejo, pois "[...] você não pode ter uma razão para fazer algo, a menos que você tenha um desejo genuíno.” (DWORKIN, 2011, p. 49). Julgamentos morais dependem apenas do que as pessoas desejam. Dworkin assume uma perspectiva cética em relação à verdade moral, pois nega a possibilidade de razões categóricas, ou seja, razões que não dependem de desejos ou de preferências. O ceticismo externo de status, por sua vez, considera a moralidade como um empreendimento mal compreendido, pois não se pode afirmar a verdade ou a falsidade das proposições de primeira ordem.

No ensejo, o ceticismo interno pressupõe que os julgamentos morais só são verdadeiros quando extraídos dos costumes de uma comuni- 
dade cultural específica e que são falsos a menos que sejam suscetíveis de aceitação por qualquer cultura. ${ }^{4}$ Nossas crenças morais são provocadas por se desenvolverem no interior de uma cultura específica. Diante dessa estrutura conceitual, para Dworkin, o ceticismo interno pressupõe que a moralidade surge nas práticas de comunidades particulares. Um cético interno na sua forma global poderia argumentar também que, como deus não existe, não se pode afirmar que algo é certo ou errado, pois a vontade sobrenatural seria a única base possível para a moralidade. O ceticismo interno não viola o Princípio de Hume, pois discute a moralidade a partir de uma perspectiva interna ao domínio do valor. O ceticismo interno é engajado à moralidade, rejeitando proposições de segunda ordem, mas fundamentando-se em proposições de primeira ordem.

Nesse particular, o ceticismo interno, para Dworkin (2007), assume a possibilidade de interpretação dos valores, que não são intangíveis. Não obstante, para tal perspectiva, não se pode alcançar a estrutura interna dos valores, de forma a estabelecer a concepção mais razoável, pois a metodologia de justificação dos valores confronta-se com a questão da indeterminação, da incerteza e da incomensurabilidade. O ceticismo interno enfrenta as questões da moralidade a partir da constatação da indeterminação e da incomensurabilidade nos julgamentos de valor, o que conduz à teoria da "nenhuma resposta correta". O domínio do valor - que inclui a moralidade, a ética e o direito - caracteriza-se por uma indeterminação.

Em contraposição aos céticos externos, os céticos internos não refutam as proposições substantivas, pois a própria alegação de indeterminação do julgamento de valor já é uma proposição substantiva que pressupõe um limite na possibilidade de justificação objetiva dos julgamentos de valor. Dworkin contrapõe-se à tese da impossibilidade de alcançar a

4 Em "Objective and Truth: You'd Better Believed it", Dworkin delineia a crítica ao ceticismo interno: "[...] Qualquer argumento bem-sucedido - e inteligível - de que as proposições valorativas não são nem verdadeiras nem falsas, deve ser interno ao domínio do valor e não arquimediano. Assim, por exemplo, a tese que não há nenhuma resposta correta à pergunta se o aborto é mau, é, em si mesma, uma proposição moral substantiva, que deve ser julgada e avaliada da mesma forma como qualquer outra proposição moral substantiva. [...]" (DWORKIN, 1996, p. 89) 
resposta correta para questões jurídicas difíceis e de que não seria possível estabelecer qual argumento é melhor do que o outro.

Dessa maneira, a indeterminação pressupõe que as premissas da argumentação não podem ser consideradas nem verdadeiras nem falsas. Para Dworkin (2011), a incerteza, por sua vez, é a impossibilidade de estabelecer qual das argumentações é mais convincente. Trata-se, portanto, da posição padrão dos julgamentos de valor, permitindo a possibilidade de uma justificação normativa no domínio do valor. Mas a questão fundamental é: a unidade entre os valores pode ser alcançada? Mesmo em caso de conflito, é possível que se tenha que eleger um deles? Para responder a essas questões, é fundamental aprofundar-se na reflexão sobre o pluralismo de valores.

\section{O Ouriço e a Raposa}

O pluralismo de valores é uma das questões mais discutidas na filosofia política contemporânea. Essa temática é analisada por Dworkin em Justice for Hedgehogs (2011), em que enfrenta a problemática da contraposição entre monismo e pluralismo de valores. O título da obra de Dworkin é uma referência ao poema de Arquíloco, mencionado por Isaiah Berlin em seu livro (1993), The Hedgehogs and the Fox: An Essay on Tolstoy's View of History, no qual reflete sobre monismo e pluralismo, lecionando que:

[...] de um lado, aqueles que relacionam tudo a uma única visão central, um sistema, mais ou menos coerente ou articulado, na forma em que compreendem, pensam e sentem - um único princípio universal organizador, nos termos de que sozinhos tudo que são e dizem possui significado - e, no outro lado, aqueles que perseguem muitos objetivos, frequentemente não relacionados e mesmo contraditórios, e se forem conectados, são simplesmente em alguma maneira de facto, por alguma causa psicológica ou fisiológica, e não relacionado a nenhum princípio moral ou estético. [...] (BERLIN, 1993, p. 436) 
Assim, a temática do confronto entre pluralismo e monismo é enfrentada por Berlin, no artigo Dois Conceitos de Liberdade (2002), no qual o pluralismo é defendido frente ao perigo do monismo moral. Resgatando as ideias do alemão Heine, o autor leciona que não se pode minimizar o poder das ideias, que podem ter efeitos nefastos, especialmente na política. Assim, a proposta de unificação e de harmonia de valores em uma perspectiva única, para Berlin, poderia terminar por legitimar práticas políticas totalitárias, o que revela o perigo do ouriço. Mas Dworkin enfatiza que há perigo tanto na perspectiva do ouriço, como na da raposa, pois " [...] o fato de o perigo do ouriço ser maior do que o da raposa, como pensava Berlin, parece depender, em grande parte, da questão de lugar e tempo." (DWORKIN, 2010, p. 152). Na década de 1950, quando Berlin escreveu essa obra, a civilização tinha mais a temer o ouriço.

Contudo, no atual Estados Unidos e em outras democracias ocidentais, a raposa pode ser o animal mais ameaçador. Berlin defendia que os valores são objetivos, mas que existem conflitos irresolúveis entre valores verdadeiros. Para Berlin, a proposta de conciliar os valores em uma rede harmoniosa é não apenas inalcançável, mas também incoerente, pois “[...] o fato de garantir ou proteger um valor, implica, necessariamente, abandonar outros ou fazer concessões" (DWORKIN, 2010, p. 153-154). Não obstante Dworkin sublinhe os perigos decorrentes da defesa do ouriço, ele também analisa criticamente a perspectiva das raposas, sublinhando que:

[...] É verdade que há perigos no ouriço, mas não devemos nos esquecer que também os há na raposa. Assim como os tiranos têm tentado justificar grandes crimes apelando à ideia de que todos os valores morais e políticos se unem em uma visão harmoniosa, de importância tão transcendental que o assassinato se justifica quando está a seu serviço, também outros crimes morais tem sido justificados pela atração pela ideia oposta, a de que valores políticos importantes entram necessariamente em conflito, que não se pode defender escolha entre eles como a única escolha correta, e que sacrifícios em algumas das coisas que nos são caras são, portanto, inevitáveis. [...] (DWORKIN, 2010, p. 150-151) 
Em suma, Dworkin exemplifica o conflito irresolúvel entre liberdade e igualdade: se impostos altos são necessários para minimizar as disparidades econômicas entre os cidadãos mais pobres e os mais ricos, promovendo a igualdade, então a tributação não pode ser concebida como uma violação da liberdade dos ricos. Sob essa ótica, “[...] a propriedade que lhes é tomada por meio de impostos não lhes pertence legitimamente." (DWORKIN, 2010, p. 160). A questão problematizada por Dworkin é investigar se os valores políticos são independentes entre si ou se são interdependentes de forma a se unirem em uma rede harmoniosa.

Aplicando tal compreensão ao caso específico da temática da anencefalia, o fato é atípico, mas ainda que se defenda haver potencialidade de vida, os direitos reprodutivos, os princípios da dignidade da pessoa humana, da legalidade, da liberdade e da autonomia da vontade, devem ser analisados de forma interligada e interdependente com o da dignidade do feto.

\section{Alguns Aspectos do Julgamento da ADPF n. 54}

A questão essencial do debate teórico envolvido na questão da ADPF n. 54 constitui, para Luis Roberto Barroso,

[...] se, ao declarar a não incidência do Código Penal a uma determinada situação, estaria o STF interpretando a Constituição - que é o seu papel - ou criando uma nova hipótese de não punibilidade do aborto, em invasão da competência do legislador. (BARROSO, 2006, p. 700)

E conclui: "Como se sabe, o Tribunal, por maioria, conheceu da ação, reconhecendo tratar-se de uma questão de interpretação constitucional e não de criação de direito novo.” (BARROSO, 2006, p. 701). O Código Penal não pune nem o aborto necessário nem o humanitário. $\mathrm{Ou}$ seja, não pune o aborto quando não há outro meio de salvar a vida da gestante nem o aborto em que a gravidez é resultante de estupro. A questão da anencefalia pressupõe uma interpretação evolutiva, pois não foi ex- 
pressamente contemplada no artigo 128 do Código Penal como excludente de ilicitude.

Nesse contexto, quando editada a Parte Especial do Código Penal, os recursos tecnológicos eram escassos, inviabilizando o diagnóstico de anomalias como a anencefalia. O pedido inicial da ADPF n. 54 era o de que o STF declarasse a não incidência da criminalização da antecipação terapêutica à luz da Constituição Federal e dos princípios a ela inerentes por meio de uma interpretação evolutiva que permite a adaptação do texto legal à evolução da sociedade. Assim, “[...] impor à mulher o dever de carregar por nove meses um feto que sabe, com plenitude de certeza, não sobreviverá, causando-lhe dor, angústia e frustração, importa violação de ambas as vertentes de sua dignidade humana". (BARROSO, 2006, p. 684)

Nesse cenário, o pedido final constitui a declaração de inconstitucionalidade, com eficácia abrangente e efeito vinculante da interpretação dos artigos 124, 126, e 128, I e II do Código Penal, como impeditiva da interpretação que criminaliza a antecipação terapêutica de parto. Em $1^{\circ}$ de julho de 2004, o pedido liminar foi concedido pelo Min. Marco Aurélio Mello, assegurando o direito da gestante em optar pela antecipação terapêutica do parto, se for comprovada a anencefalia por laudo médico. A liminar apenas suscitou efeitos por mais três meses, pois, em 27 de abril de 2005, foi tornada sem efeito pelo Plenário do STF, por sete votos a quatro; entretanto, igual votação admitiu que a ADPF fosse processada para que seu mérito fosse apreciado.

Nessa ocasião, os Ministros Carlos Ayres de Britto, Gilmar Mendes, Sepúlveda Pertence e Nelson Jobim posicionaram-se rejeitando o argumento segundo o qual seria incabível a propositura da ADPF n. 54. Permaneceram vencidos os Ministros Eros Grau, Cesar Peluso e Ellen Gracie, que não conheceram da ação, sob o argumento segundo o qual a mesma ofenderia a separação de poderes, criando uma nova hipótese de exclusão da ilicitude para o aborto.

Com efeito, no julgamento de mérito realizado em abril de 2012, o Ministro Relator, Marco Aurélio Mello e o Min. Celso de Mello destacaram que a Constituição consagra a laicidade, impedindo que o Estado 
intervenha em assuntos religiosos. De acordo com o Min. Marco Aurélio Mello, a laicidade do Estado atuaria de modo dúplice: salvaguardaria as diversas confissões religiosas do risco da intervenção estatal e impediria que dogmas da fé determinassem o conteúdo dos atos estatais. Nas palavras do Min. Marco Aurélio, “[...] concepções morais religiosas, quer unânimes, quer majoritárias, quer minoritárias, não podem guiar as decisões estatais, devendo ficar circunscritas à esfera privada" (BRASIL, 2012i). As garantias do Estado secular e da liberdade religiosa impedem que o Estado utilize seu poder coercitivo para endossar concepções morais religiosas, visando a coagir os cidadãos a observá-las.

Nessa linha de raciocínio, o Ministro relator citou a Resolução n. 1.752/2004 do Conselho Federal de Medicina, que consignou serem os anencéfalos natimortos cerebrais. Assim, o direito à vida de um feto inviável não pode prevalecer sobre a dignidade da pessoa humana, privacidade, saúde e integridade física e psicológica da mãe. Nas palavras do Ministro relator,

[...] o anencéfalo jamais se tornará pessoa. Não se cuida de vida em potencial, mas de morte segura. $\mathrm{O}$ fato de respirar e ter batimento cardíaco não altera essa conclusão, até porque, como acentuado pelo Dr. Thomaz Rafael Gollop, a respiração e o batimento cardíaco não excluem o diagnóstico de morte cerebral. (BRASIL, 2012i)

Em síntese, o Marco Aurélio Mello também refutou o argumento de que se trata de aborto eugênico, pois não se cuida de feto portador de deficiência grave que permita sobrevida extrauterina. Inexiste direito à vida dos anencéfalos, pois anencefalia e vida são termos antiéticos. Ademais, nas décadas de 1930 e 1940, a medicina não possuía recursos tecnológicos para identificar previamente a anencefalia.

Em face desta leitura, o Ministro relator citou o depoimento do Dr. Jorge Andalaft Neto, representante da Federação Brasileira das Associações de Ginecologia e Obstetrícia, que enfatizou o fato de a gestação de feto anencéfalo envolver maiores riscos, tendo em vista dados da Organização Mundial de Saúde e do Comitê da Associação de Ginecologia e Obstetrícia Americana. Impor a manutenção da gravidez pode implicar o 
aumento da morbidade e dos riscos do parto e do pós-parto, além de consequências psicológicas severas. Por outro lado, Celso de Mello, Marco Aurélio Mello e Rosa Weber destacaram que inexiste direito à vida, tendo em vista o conceito jurídico de morte previsto na Lei n. 9.394/97. Para o Min. Marco Aurélio Mello, eventual direito à vida do anencéfalo cederia, em juízo de ponderação, em prol dos direitos à dignidade da pessoa humana, à liberdade no campo sexual, à autonomia, à privacidade, à integridade física psicológica e moral e à saúde.

Ademais, de acordo com o Ministro Luiz Fux, há uma tensão entre a pretensão punitiva do Estado e os direitos individuais. Na sua percepção,

[...] a criminalização de condutas, a imposição de penas e o regime de sua execução deverão realizar os desígnios da Constituição, precisam ser justificados e não poderão ter natureza arbitrária, caprichosa ou desmesurada. (BRASIL, 2012h)

Em suma, deverão observar o princípio da razoabilidade-proporcionalidade, inclusive e especialmente na vedação do excesso.

Nesse quadro teórico, o Min. Luiz Fux considerou que essa ponderação de preceitos se caracterizaria como um estado de necessidade justificante, desenvolvido na jurisprudência alemã. Trata-se de estado de necessidade supralegal, a fim de adequar a lei às necessidades sociais. Diferentemente, os Ministros Celso de Mello, Marco Aurélio Mello, Rosa Weber e Carlos Ayres de Britto defenderam a atipicidade da antecipação. E, para Celso de Mello, ainda que não se entenda típico, não há delituosidade por inexigibilidade de conduta diversa. Não se pode obrigar a mulher a prolongar a gravidez, com prejuízos à saúde física e devido aos altos índices de letalidade, segundo o depoimento do Dr. José Aristodemo Pinotti, Professor da Unicamp. (BRASIL, 2012d)

O Min. Marco Aurélio Mello salientou também que inexiste direito à vida dos anencéfalos, mas que, ainda que existisse, não seria absoluto, tendo em vista o artigo $5^{\circ}$, inciso XLVII da CF, que admite a pena de morte em caso de guerra declarada na forma do artigo 84, inciso XIX. Ademais, o próprio Código Penal prevê, como causa excludente da ili- 
citude, o aborto ético ou humanitário no caso de gravidez resultante de estupro. Mencionou que "[...] além de o direito à vida não ser absoluto, a proteção a ele conferida comporta diferentes gradações consoante enfatizou o Supremo no julgamento da ADI n. 3.510.” (BRASIL, 2012i). E conclui: "[...] se a proteção a um feto saudável é passível de ponderação com direitos da mulher, com maior razão o é eventual proteção dada ao feto anencéfalo.” (BRASIL, 2012i)

Diferentemente, o Min. Gilmar Mendes considerou inadequado tratar a antecipação terapêutica da gestação de anencéfalos como atípico, pois parte da sociedade brasileira defenderia a vida e a dignidade desses fetos. Alegou a possibilidade de defender o aborto de fetos anencéfalos a partir das opções legislativas de excludentes da ilicitude já existentes no Código Penal, sendo hipótese de estado de necessidade. Constatou que o aborto de fetos anencéfalos deveria estar compreendido entre as causa excludentes da ilicitude previstas no Código Penal, mas seria inimaginável para o legislador de 1940, pelas limitações tecnológicas existentes, incluir a hipótese no texto legal. (BRASIL, 2012f)

Nessa perspectiva, o Min. Luiz Fux destacou que o princípio da proporcionalidade não se restringe à categoria de proibição de excesso, contemplando também um dever de proteção por parte do Estado, inclusive quanto a violações contra direitos fundamentais de terceiros: a violação da proibição de insuficiência. A violação da proibição de insuficiência está associada a uma omissão do poder público quanto ao cumprimento de um imperativo constitucional de tutela ou dever de proteção. (BRASIL, 2012g)

Diante do exposto, depreende-se que o princípio da razoabilidade-proporcionalidade, além de parâmetro de validade para restrições a direitos fundamentais, também atua na dupla dimensão de proibição do excesso e da insuficiência. A Ministra Carmem Lúcia destacou que a questão discutida seria o direito à vida e à liberdade, considerada a possibilidade jurídica de a grávida de feto anencéfalo escolher qual seria o melhor caminho a ser seguido, quer continuando, quer interrompendo a gravidez. Reportou-se também ao princípio constitucional da dignidade da pessoa e ao direito à saúde. (BRASIL, 2012a) 
Sob esse aspecto, o Min. Celso de Mello mencionou que a Declaração Americana sobre Direitos da Pessoa Humana e Pacto Internacional das Nações Unidas sobre Direitos Civis e Políticos consagraram a inviolabilidade do direito à vida, mas não incorporaram a noção de direito à vida desde a concepção. Assinalou que, de acordo com a Resolução n. 1.752/2004 do Conselho Federal de Medicina, o anencéfalo é um natimorto cerebral, destituído de viabilidade e de autonomia existencial em ambiente extrauterino. Salientou que a anencefalia implica variações no líquido amniótico e complicações no parto. (BRASIL, 2012 d)

É de se mencionar que, para o Min. Carlos Ayres de Britto, a gravidez se destina à vida, não à morte. A vida humana surge com o zigoto, mas não se deve confundir embrião de vida humana com vida humana embrionária (BRASIL, 2012c). De um lado, os Ministros Celso de Mello e Gilmar Mendes assinalaram a relevância da pluralização do debate constitucional, garantindo legitimidade democrática ao STF.

De outro lado, o Ministro Gilmar Mendes enfatizou a relevância do amicus curiae como fonte de informação para a Corte, permitindo a participação plural da sociedade com a manifestação de diversas organizações da sociedade, inclusive as religiosas em audiências públicas. Gilmar Mendes refutou a compreensão de que o Estado laico previsto na Constituição impede a manifestação de entidades religiosas no debate público, pois os argumentos de entidades religiosas podem ser considerados pelo Estado, manifestando-se sob a forma de razões públicas e não somente como razões religiosas. Destacou a concretização de comunidade aberta de intérpretes da Constituição, tendo em vista que a participação de diversos grupos cumpre uma função de integração no Estado de direito, com novas possibilidades de legitimação das decisões. (BRASIL, 2012d; BRASIL, 2012f)

De fato, Gilmar Mendes pressupôs um norte interpretativo a partir da leitura do aborto humanitário, que também resguarda a saúde psíquica da gestante, sendo necessário adaptar as leis a novos aspectos da realidade social para vislumbrar causas supralegais de exclusão da juridicidade e culpabilidade. Em sentido diametralmente oposto, o Ministro Ricardo Lewandowski lecionou que a técnica de interpretação conforme, ainda 
que legítima e desejável, depara-se com dois obstáculos intransponíveis: "De um lado, não é dado ao hermeneuta afrontar a expressão literal da lei; de outro, não pode ele contrariar a vontade manifesta do legislador e, muito menos, substituir-se a ele." (BRASIL, 2012j)

Desse modo, o juiz, deparando-se com uma lei cujo texto e sentido sejam claros e inequívocos, não deve nunca dar-lhe sentido oposto mediante o emprego do método de interpretação conforme a Constituição. Nesse ponto, a interpretação, conforme a Constituição pode implicar: a) uma delimitação do conteúdo da norma; b) sua não aplicação a um determinado contexto fático; c) a inconstitucionalidade de uma das normas decorrentes do texto, sendo que não há necessidade de uma declaração de inconstitucionalidade da norma, que permanece íntegra em ambas as situações.

No ensejo, a denominada técnica de "interpretação conforme a Constituição", que tem sido desenvolvida pelo STF, ocorre quando, diante de uma variedade de métodos interpretativos, o Tribunal opta por uma linha de interpretação possível a respeito de uma norma legal, adequando-a a um determinado contexto fático. Mas, para o Min. Ricardo Lewandowski, a interpretação conforme a Constituição não deve ser utilizada para alterar conteúdos normativos, pois isso é tarefa do legislador e não do tribunal constitucional. Em suma, o STF deve restringir sua atuação ao papel de legislador negativo, extirpando do ordenamento jurídico as normas constitucionais. Além disso, salientou, da mesma forma como o Ministro César Peluso, o risco de que, se julgada procedente a ADPF n. 54, mulheres irão pleitear igual tratamento jurídico a outras anomalias.

Outrossim, o Ministro Ricardo Lewandowski afastou o argumento segundo o qual, à época da promulgação do Código Penal, não existiriam métodos científicos para detectar a anencefalia. Frisou que, caso desejasse, o Congresso Nacional poderia ter alterado a legislação para incluir o aborto de fetos anencéfalos dentre as hipóteses de interrupção da gravidez isenta de pena. Quando a lei fosse clara, não haveria espaço para a interpretação. Por sua vez, o Min. César Peluso, também vencido, estabeleceu uma diferenciação entre a questão da anencefalia e a temática das células- 
-tronco embrionárias, em que se tratava de embrião excedente que sequer fora implantado no útero e jamais viria a sê-lo.

Nessa trajetória jurídica, o Min. Peluso ressaltou a necessidade de preservar a dignidade da vida intrauterina Destacou que todos os fetos anencéfalos, a menos que já estivessem mortos, seriam dotados de capacidade de movimento autógeno vinculado ao processo contínuo da vida. A dignidade humana independe das deficiências que o feto possa porventura vir a ter, sendo insuscetíveis de o transformarem em coisa. Na sua percepção, transformar o feto em objeto de disposição alheia, é equipará-lo a coisa e somente ela é objeto de disposição alheia, pois ser humano é sujeito de direito. A vida humana com sua dignidade intrínseca não pode ser relativizada fora das hipóteses legais.

Na sua interpretação, reduzir o anencéfalo à condição de lixo, implica a aproximação com práticas eugênicas. A analogia com a presunção de morte por cessação da atividade encefálica, visando retirada de tecidos, órgãos para fins de transplante, não é adequada, pois nesse caso o aborto não visa a salvar a vida de alguém. A vida humana, para o Min. César Peluso, não pode ser relativizada, sendo um valor supremo e inegociável. A viabilidade de vida extrauterina não é requisito para caracterização do crime de aborto.

No entanto, sustenta-se que o Estado não pode funcionalizar as mulheres, tratando-as como um meio, violando sua igualdade. É verdade que o Brasil já tem algumas medidas de estabelecimento de ações positivas para prevenir a anencefalia, viabilizando ácido fólico na rede básica de saúde para acesso de todas as mulheres no período pré-gestacional e gestacional. Propugna-se que o Estado deve criar políticas públicas de assistência médica e psicológica às gestantes de fetos anencéfalos, incentivando as mulheres a exercerem seus direitos de forma responsável.

Nesse aspecto, a partir de A Justiça de Toga (2010), em Is Democracy Possible Here? (2006), em O Domínio da Vida (2003), e agora, em Justice for Hedgehogs (2011), Dworkin estabelece o conceito de responsabilidade como o principal aspecto da teoria da interpretação. Feitas essas considerações, passa-se à análise do julgamento da ADPF n. 54 à luz da filosofia política de Dworkin. 


\section{O Julgamento da ADPF n. 54 à Luz da Filosofia de Ronald Dworkin}

É mister sublinhar que a preocupação fundamental de Dworkin, em Domínio da Vida (2003a), volta-se para os limites da decisão estatal, evitando a coerção governamental em questões como, por exemplo, qual a melhor forma de respeitar a santidade da vida. $\mathrm{O}$ autor parte da distinção entre duas formas de interesse do governo na proteção da vida humana: derivativa e independente. Quando se fala de um interesse derivativo, pressupõe-se que o feto é uma pessoa constitucional que

[...] tem direitos e interesses a partir da concepção, inclusive o direito à vida, e que o governo deve protegê-los tanto quanto protege os direitos e interesses de qualquer indivíduo que esteja sujeito a sua autoridade. (DWORKIN, 2003a, p. 149)

Diferentemente, o governo pode reivindicar um interesse independente de proteger a vida do feto, objetivando proteger a vida humana como algo sagrado, cujo valor intrínseco independe de ser o feto uma pessoa constitucional.

Diante dessa estrutura conceitual, se a vida possui valor intrínseco, então

[...] qualquer comunidade política tem a preocupação legítima de proteger a santidade ou inviolabilidade da vida humana, exigindo que seus membros reconheçam o seu valor intrínseco ao tomarem duas decisões individuais. (DWORKIN, 2003a, p. 209-210)

A teoria de Dworkin, em Domínio da Vida (2003a), contempla um espaço amplo para a moralização governamental. O governo pode encorajar a responsabilidade, mas não coagir a última decisão. Desse modo, se a vida do feto possui valor intrínseco, esta santidade da vida é um valor controverso e contestável.

Nesse particular, questiona Dworkin (2003a, p. 211): “[...] o Estado protege melhor um valor contestável ao incentivar as pessoas aceitarem- 
-no como contestável, compreendendo que são responsáveis por decidir por si próprias o que isso significa?"

De acordo com esse ponto de vista, o Estado pretende estimular a ideia de responsabilidade, segundo a qual o governos deve pretender que seus cidadãos reflitam sobre as decisões referentes ao valor intrínseco da vida como questões de importância moral. ${ }^{5}$

Dessa maneira, partindo do interesse derivativo e da ideia de responsabilidade, o Estado não pode usar o seu aparato repressivo para sustentar concepções morais hegemônicas que violem a liberdade dos indivíduos, impondo uma concepção sobre o valor intrínseco da vida. Para Dworkin, a Constituição norte-americana permite que os governos dos Estados persigam o objetivo da responsabilidade, estimulando que os cidadãos decidam de forma responsável sobre o valor intrínseco da vida, ao invés de forçá-los a uma posição consensual. Não obstante, de acordo com James Fleming, alguns críticos não esperariam uma proposta de compatibilização entre liberdade pessoal e proteção governamental da esfera moral:

[...] Segundo, críticos e aliados frequentemente associam Dworkin com a noção de direitos como trunfos e, portanto, com a ideia de que levar os direitos a sério praticamente impossibilita reconciliar direitos ou balanceá-los com a preocupação governamental com a esfera moral. Realmente, alguns leitores podem ter esperado um livro de Dworkin sobre o direito à autonomia procriativa e o di-

\footnotetext{
5 Sob esse prisma, o autor, em passagem elucidativa, menciona que: “[...] Um Estado pode pretender que seus cidadãos tratem as decisões relativas ao aborto como questões de importância moral; que reconheçam que os valores intrínsecos fundamentais estão em jogo nessas decisões e decidam reflexivamente - não por uma conveniência imediata, mas a partir de uma convicção ponderada e amadurecida. [...] Se pretendemos a responsabilidade, no final devemos deixar os cidadãos livres para decidir como lhes parecer melhor, pois é isso que implica a responsabilidade moral. Contudo, se nosso objetivo for a conformidade, exigiremos, ao contrário, que os cidadãos ajam de uma maneira que poderia ser contrária a suas próprias convicções morais; isso os desestimula, em vez de incentivá-los a desenvolver seu próprio senso de quando e por que a vida é sagrada. [...] (DWORKIN, 2003a, p. 210)
} 
reito de morrer para defender esses direitos somente com base no argumento da liberdade pessoal. E eles podem ter esperado que Dworkin argumentasse que esses direitos se sobrepõem à própria preocupação relativa ao ambiente moral que ele aqui reconhece como parte de nossa herança política e do direito constitucional. [...] (FLEMING, 2009, p. 841)

Nesse contexto, Fleming analisa duas críticas que alguns autores têm feito a Dworkin. Em primeiro lugar, a compreeensão de que levar os direitos a sério exclui tomar a responsabilidade a sério, impedindo a promoção governamental do ambiente moral. Em segundo lugar, a acusação de que

[...] a sua concepção de direitos como trunfos, seja direitos à privacidade ou à autonomia, exige que a realização dos direitos seja isolada do escrutínio, persuasão ou exortação moral pelo governo. (FLEMING, 2009, p. 844)

No entanto, tais críticas podem ser superadas, pois Dworkin insiste na distinção entre a pretensão do governo de encorajar a responsabilidade e coagir em conformidade com a concepção majoritária sobre o valor intrínseco da vida. Para Fleming,

Dworkin, ao distinguir entre responsabilidade e coerção, está afirmando que o governo não está promovendo a responsabilidade, a menos que respeite o direito do indivíduo de decidir em última análise por si próprio. (FLEMING, 2009, p. 846)

Trata-se, portanto, da responsabilidade como autonomia. Em suma, em Justice for Hedgehogs (2011), o conceito de responsabilidade, que já havia sido objeto de análise em o Domínio da Vida (2003a), é analisado de forma mais ampla e torna-se um aspecto fundamental para a teoria da justificação. Ele reitera sobre a necessidade de levar os direitos a sério, concebendo-os como trunfos. E ele continua a usar o discurso da responsabilidade, quando aduz que o governo deve respeitar a responsabilidade pessoal dos indivíduos por suas próprias vidas. Feitas essas considera- 
ções, é mister elucidar em que medida o voto do Ministro Gilmar Mendes teria concretizado implicitamente a ideia de responsabilidade.

Assim, o Ministro Gilmar Mendes acrescentou ao dispositivo da decisão prolatada pelo Colegiado determinadas medidas solicitadas ao Ministério da Saúde e ao Conselho Federal de Medicina, para assegurar condições de segurança do diagnóstico da anencefalia e de realização do procedimento cirúrgico, sendo acompanhado pelo Ministro Celso de Mello. As condições seriam as seguintes: a) atestado subscrito por, no mínimo, dois médicos especialistas e segundo técnicas de exames suficientemente seguras; b) observância do período de três dias entre a data do diagnóstico e da intervenção cirúrgica; e; c) disponibilização, por parte do Poder Público, em favor de gestantes de menor poder aquisitivo, de acompanhamento psicológico, tanto antes quanto depois do procedimento cirúrgico. Tal condição pretendia determinar ao Ministério da Saúde a criação de serviços de saúde qualificados para as mulheres que decidirem pela continuidade da gravidez de feto anencéfalo (inclusive atendimento com assistência terapêutica aos transtornos mentais decorrentes da anencefalia). Nesse ponto, os Ministros Gilmar Mendes e Celso de Mello ficaram vencidos apenas neste acréscimo de condições ao dispositivo da decisão. (BRASIL, 2012f; BRASIL, 2012d)

Nesse cenário, a quarta condição, proposta pelo Min. Gilmar Mendes, revelou implicitamente a consagração da ideia dworkiniana da responsabilidade, mas infelizmente, foi rejeitada pelo Plenário. A postura do Ministro Gilmar Mendes, portanto, não pretendeu impor uma concepção majoritária sobre o valor intrínseco da vida e a dignidade do feto anencéfalo, mas buscou encorajar as gestantes de fetos anencéfalos a refletirem de forma responsável sobre a continuidade ou não da gravidez.

De outro lado, a ideia de integridade revelou-se fundamental no voto do Min. Marco Aurélio, que resgatou a argumentação do seu voto no julgamento da ADI n. 3.510/DF ajuizada pela Procuradoria Geral da República e julgada em 29 de maio de 2008, em que assentou que inexiste violação na utilização de células tronco embrionárias em pesquisas científicas, uma vez que, 
[...] sob o ângulo biológico, o início da vida pressupõe não só a fecundação do óvulo pelo espermatozóide, como também a viabilidade, elemento inexistente quando se trata de feto anencéfalo, considerado pela medicina como natimorto cerebral...". (BRASIL, 2008)

Ademais, mencionando o voto do Ministro Carlos Ayres de Britto na mesma ADI n. 3.510/DF, ele destacou que a Constituição Federal, quando se reporta aos

[...] direitos da pessoa humana e até dos direitos e garantias individuais como cláusula pétrea, está falando de direitos e garantias do indivíduo-pessoa, que se faz destinatário dos direitos fundamentais à vida, à liberdade, à igualdade, à segurança e à propriedade. (BRASIL, 2012)

E no caso do anencéfalo, não há, nem nunca haverá indivíduo-pessoa. No mesmo sentido, a Ministra Rosa Weber também reportou-se a ADI n 3.510/DF, destacando que o embrião fecundado in vitro não conformaria ser vivo no sentido do disposto do artigo $5^{\circ}$, caput, da Constituição Federal, haja vista que, para ser vida cuja proteção interessa ao direito, é necessária a possibilidade de desenvolvimento do indivíduo com capacidades mínimas intrínsecas ao ser humano, não apenas possíveis condições biológicas.

Com efeito, percebe-se a coerência moral do julgamento, que atendeu plenamente ao ideal de integridade descrito por Dworkin. Em suma, para Dworkin, a contraposição entre originalistas e não originalistas é superada em favor de uma perspectiva que concebe o direito em uma dimensão de integridade. $\mathrm{O}$ direito como integridade nega uma concepção do fenômeno jurídico como reflexo de práticas convencionais que são voltadas para o passado, ou filosofias pragmatistas voltadas para o futuro. Seria necessário articular ambos os elementos, interpretando a moralidade institucional de uma comunidade como um grande romance em cadeia.

Em síntese, o direito como integridade rejeita a problemática da existência ou não de discricionariedade judicial, superando a contraposição entre interpretativistas e não interpretativistas com base na própria 
leitura moral da Constituição. Há uma ampliação das possibilidades de atuação do poder judicial sem que tal perspectiva implique usurpação das funções legislativas. Em suma, a própria abertura do texto constitucional traz novos horizontes interpretativos com base em princípios eleitos pelo povo.

Em face desta leitura, se os indivíduos que compartilham as práticas sociais, estabelecem práticas interpretativas, a ideia de responsabilidade torna-se fundamental na fase de justificação. A interpretação, como fenômeno social, pressupõe uma prática social. O processo interpretativo decorre de práticas sociais compartilhadas nas quais se está inserido. É possível alcançar a verdade na interpretação quando se interpreta uma prática social e se identifica o seu propósito. Assim, não se trata de descrever as práticas sociais, mas, sim de compreender o seu objetivo.

Para Dworkin, o respeito pela dignidade humana implica em duas exigências: (1) o princípio do autorrespeito, segundo o qual "[...] cada pessoa deve levar a sua própria vida a sério; ela deve aceitar que é uma questão importante que sua vida seja uma realização de sucesso e não um desperdício de oportunidade." (DWORKIN, 2011, p. 203). O princípio do autorrespeito não é um princípio moral. Ele descreve uma atitude que o indivíduo deve ter em relação à sua própria vida, de forma que "[...] cada um de nós trate sua própria vida como tendo um tipo de importância." (DWORKIN, 2011, p. 205)

Nesse quadro teórico, o princípio da autenticidade, por sua vez, pressupõe que

[...] cada pessoa tem uma responsabilidade especial e pessoal de identificar o que conta como sucesso em sua própria vida; ela tem uma responsabilidade pessoal de tornar a sua vida uma narrativa ou estilo coerente que ela própria endossa. (DWORKIN, 2011, p. 204)

O que o princípio da autenticidade considera como crucial não é que nós levemos uma vida diferentemente dos outros, mas uma vida em resposta à nossa situação e aos valores que consideramos apropriados. De acordo com Dworkin, esses princípios desempenham um triplo papel: (1) 
fornecem um parâmetro sobre o que se deve fazer para viver bem; (2) elucidam os direitos que os indivíduos possuem em face da comunidade política; (3) eles são a base para os deveres morais que se tem uns em relação aos outros.

Nessa perspectiva, Dworkin (2011, p. 366) estabelece uma diferenciação entre dois tipos de liberdade: freedom e liberty. A primeira configura a liberdade total e seu poder de agir para se fazer o que se quer independentemente de restrições governamentais ou impostas por outros indivíduos; a segunda constitui a parte da liberdade-freedom que a comunidade política não pode restringir, sob pena de comprometer a sua dignidade. Dworkin estabelece três tipos de argumentos para justificar a liberdade. Em primeiro lugar, precisam-se de algumas liberdades, especialmente a liberdade de expressão, porque são necessárias para um sistema justo e democrático de governo.

Em segundo lugar, tem-se o direito ao que denomina-se de independência ética, ou seja, o direito de fazer escolhas fundamentais sobre o significado e a importância da vida humana para nós mesmos. Por fim, novamente com base na independência ética, tem-se o direito de não ser negada qualquer liberdade quando a justificativa do governo repousa na popularidade ou em uma suposta superioridade de alguma concepção sobre a melhor maneira de viver. Tal compreensão assume relevância na temática da anencefalia e serve para minimizar a crítica do Min. Ricardo Lewandowski sobre os limites da atuação do STF, tendo em vista que a necessidade de ampliação da atuação jurisdicional tornou-se necessária para garantir a independência ética de gestantes de fetos anencéfalos.

\section{Conclusões}

A interpretação é fundamental para teoria dworkiniana. No julgamento da ADPF n. 54, o STF conseguiu justificar de forma coerente os conceitos que integram o domínio do valor, articulando-os de maneira que um complemente o sentido do outro, inexistindo conflito. Tal perspectiva, aplicada à interpretação constitucional da temática da ADPF n. 54, supera os argumentos do Min. Ricardo Lewandowski no sentido de 
que a técnica de Interpretação conforme a Constituição não pode ser resgatada para modificar conteúdos normativos, porquanto tal postura seria função do legislador.

Assim, ainda que se argumente pela defesa da potencialidade de vida, os direitos reprodutivos da gestante, assim como os princípios da dignidade da pessoa humana, da autonomia da vontade, da legalidade, da privacidade e da liberdade devem ser interligados em uma rede harmoniosa com a dignidade do feto por meio da técnica da Interpretação conforme a Constituição. Portanto, a moral, o direito e a ética integram a esfera do valor, pressupondo uma metodologia específica: a interpretação. Ademais, a autonomia reprodutiva da gestante de feto anencéfalo integra a esfera da liberty, que não pode ser restringida pela comunidade política, sob pena de comprometer a sua dignidade.

De um lado, a quarta condição, proposta pelo Min. Gilmar Mendes e acompanhada pelo Min. Celso Mello, consagrou implicitamente a ideia dworkiniana de responsabilidade, estimulando as gestantes de fetos anencéfalos a refletirem responsavelmente sobre a continuidade da gestação como uma questão de importância moral. Infelizmente, tal condição foi superada pelo Plenário do STF. De outro lado, os princípios constitucionais da dignidade humana, da liberdade, da autodeterminação pessoal e da intimidade foram resgatados pelo Min. Celso Mello, de forma a atribuir integridade moral ao ordenamento jurídico.

Disso se infere que a ideia de integridade revela-se fundamental, pois, no julgamento da ADI n. 3.510/DF estabeleceu-se que inexiste violação de direito à vida na utilização de células-tronco embrionárias em pesquisas científicas, uma vez que não seriam vidas em potencial. Trata-se, portanto, como pretende Dworkin, de interpretar as práticas jurídicas na sua melhor luz. Em ambos os casos não há potencialidade de vida: no primeiro porque não serão implantadas no útero e, na anencefalia, porque não possuem viabilidade fora do útero.

Indubitavelmente, a concepção de dignidade humana representa um conceito jurídico indeterminado que inspira múltiplas possibilidades interpretativas. No caso específico, o Ministro Marco Aurélio Mello interpretou tal conceito à luz dos princípios constitucionais da intimidade, da 
liberdade, da autodeterminação pessoal da gestante. Percebe-se que, com base em tais princípios constitucionais de abertura argumentativa, o Min. Relator foi capaz de desenvolver uma interpretação sofisticada do conceito de "dignidade humana" capaz de resguardar uma esfera de independência ética inerente a cada indivíduo. A própria leitura moral da Constituição, a nosso ver, inspirou uma perspectiva reconstrutiva conectada à ideia de moral crítica, que rompe com autocompreensões assimétricas de mundo.

\section{Referências}

BARROSO, Luis Roberto. "Gestação de Fetos Anencefálicos e Pesquisas com Células-tronco: dois temas acerca da vida e da dignidade na Constituição". In: SARMENTO, Daniel; GALDINO, Flavio (Org.). Direitos fundamentais: estudos em homenagem ao professor Ricardo Lobo Torres. Rio de Janeiro: Renovar, 2006.

BERLIN, Isaiah. Dois Conceitos de Liberdade. In: Estudos sobre a humanidade: uma antologia de ensaios. São Paulo: Companhia das Letras, 2002.

. The Hedgehogs and the Fox: an essay on Tolstoy's View of History. New York: Simon \& Schuster, 1986.

BRASIL. Supremo Tribunal Federal. Argüição de Descumprimento de Preceito Fundamental. Anencefalia. Arguição de Descumprimento de Preceito Fundamental n. 54 ajuizada pela Confederação Nacional dos Trabalhadores da Saúde. Voto da Min. Carmem Lúcia. Plenário. Relator: Min. Marco Aurélio Mello. Brasília-DF, j.11/04/2012a. Informativo do STF n. 661. Disponível em: <http://www.stf.jus.br/ arquivo/informativo/documento/informativo661.htm\#ADPF\%20e $\% 20$ interrup $\% \mathrm{C} 3 \% \mathrm{~A} 7 \% \mathrm{C} 3 \% \mathrm{~A} 3 \mathrm{o} \% 20 \mathrm{de} \% 20$ gravidez $\% 20 \mathrm{de} \% 20$ feto $\% 20$ anenc\%C3\%A9falo\%20-\%2026>. Acesso em: 29 ago. 2012. 
. Argüição de Descumprimento de Preceito Fundamental .

Anencefalia. Arguição de Descumprimento de Preceito Fundamental n. 54 ajuizada pela Confederação Nacional dos Trabalhadores da Saúde. Voto da Min. Rosa Weber. Plenário. Relator: Min. Marco Aurélio Mello. Brasília-DF, j.11/04/2012b. Informativo do STF n. 661. Disponível em: $<$ http://www.stf.jus.br/arquivo/informativo/documento/ informativo661.htm\#ADPF $\% 20 \mathrm{e} \% 20$ interrup $\% \mathrm{C} 3 \% \mathrm{~A} 7 \% \mathrm{C} 3 \% \mathrm{~A} 3 \mathrm{o} \% 20$ de\%20gravidez\%20de\%20feto\%20anenc\%C3\%A9falo\%20-\%2026>. Acesso em: 29 ago 2012.

. Argüição de Descumprimento de Preceito Fundamental .

Anencefalia. Arguição de Descumprimento de Preceito Fundamental n. 54 ajuizada pela Confederação Nacional dos Trabalhadores da Saúde. Voto do Min. Carlos Ayres de Britto. Plenário. Relator: Min. Marco Aurélio Mello. Brasília-DF, j.12/04/2012c. Informativo do STF n. 661. Disponível em: <http://www.stf.jus.br/arquivo/ informativo/documento/informativo661.htm\#ADPF $\% 20 \mathrm{e} \% 20$ interrup $\% \mathrm{C} 3 \% \mathrm{~A} 7 \% \mathrm{C} 3 \% \mathrm{~A} 3 \mathrm{o} \% 20 \mathrm{de} \% 20$ gravidez $\% 20 \mathrm{de} \% 20$ feto $\% 20$ anenc\%C3\%A9falo\%20-\%2026>. Acesso em: 29 ago 2012.

. Arguição de Descumprimento de Preceito Fundamental .

Anencefalia. Arguição de Descumprimento de Preceito Fundamental n. 54 ajuizada pela Confederação Nacional dos Trabalhadores da Saúde. Voto do Min. Celso de Mello. Plenário. Relator: Min. Marco Aurélio Mello. Brasília-DF, j.12/04/2012d. Informativo do STF n. 661. Disponível em: $<$ http://www.stf.jus.br/arquivo/informativo/documento/ informativo661.htm\#ADPF $\% 20 \mathrm{e} \% 20$ interrup $\% \mathrm{C} 3 \% \mathrm{~A} 7 \% \mathrm{C} 3 \% \mathrm{~A} 3 \mathrm{o} \% 20$ de $\% 20$ gravidez $\% 20$ de $\% 20$ feto $\% 20$ anenc $\%$ C3\%A9falo $\% 20-\% 2026>$. Acesso em: 29 ago 2012.

. Argüição de Descumprimento de Preceito Fundamental .

Anencefalia. Arguição de Descumprimento de Preceito Fundamental n. 54 ajuizada pela Confederação Nacional dos Trabalhadores da Saúde. Voto do Min. César Peluso. Plenário. Relator: Min. Marco Aurélio Mello. Brasília-DF, j.12/04/2012e. Informativo do STF n. 661. Disponível em: <http:/www.stf.jus.br/arquivo/informativo/documento/ informativo661.htm\#ADPF $\% 20 \mathrm{e} \% 20$ interrup $\% \mathrm{C} 3 \% \mathrm{~A} 7 \% \mathrm{C} 3 \% \mathrm{~A} 3 \mathrm{o} \% 20$ de\%20gravidez\%20de\%20feto\%20anenc\%C3\%A9falo\%20-\%2026>. Acesso em: 29 ago 2012. 
. Argüição de Descumprimento de Preceito Fundamental .

Anencefalia. Arguição de Descumprimento de Preceito Fundamental n. 54 ajuizada pela Confederação Nacional dos Trabalhadores da Saúde. Voto do Min. Gilmar Mendes. Plenário. Relator: Min. Marco Aurélio Mello. Brasília-DF, j.12/04/2012f. Informativo do STF n. 661. Disponível em: <http://www.stf.jus.br/arquivo/informativo/documento/ informativo661.htm\#ADPF\%20e $\% 20$ interrup $\% \mathrm{C} 3 \% \mathrm{~A} 7 \% \mathrm{C} 3 \% \mathrm{~A} 3 \mathrm{o} \% 20$ de $\% 20$ gravidez $\% 20$ de $\% 20$ feto $\% 20$ anenc $\%$ C3\%A9falo $\% 20-\% 2026>$. Acesso em: 29 ago 2012.

. Argüição de Descumprimento de Preceito Fundamental.

Anencefalia. Arguição de Descumprimento de Preceito Fundamental n. 54 ajuizada pela Confederação Nacional dos Trabalhadores da Saúde. Plenário. Voto do Min. Joaquim Barbosa. Relator: Min. Marco Aurélio Mello. Brasília-DF, j. 11/04/2012g Informativo do STF n. 661. Disponível em: <http://www.stf.jus.br/arquivo/informativo/documento/ informativo661.htm\#ADPF\%20e\%20interrup $\%$ C3\%A7\%C3\%A3o\%20 de $\% 20$ gravidez $\% 20$ de $\% 20$ feto $\% 20$ anenc $\%$ C3\%A9falo $\% 20-\% 2026>$. Acesso em: 29 ago 2012.

. Argüição de Descumprimento de Preceito Fundamental.

Anencefalia. Arguição de Descumprimento de Preceito Fundamental n. 54 ajuizada pela Confederação Nacional dos Trabalhadores da Saúde. Voto do Min. Luiz Fux. Plenário. Relator: Min. Marco Aurélio Mello. Brasília-DF, j.11/04/2012. Disponível em: <http:/www.stf.jus.br/ arquivo/cms/noticiaNoticiaStf/anexo/ADPF54LF.pdf>. Acesso em: 29 ago 2012.

. Argüição de Descumprimento de Preceito Fundamental.

Anencefalia. Arguição de Descumprimento de Preceito Fundamental n. 54 ajuizada pela Confederação Nacional dos Trabalhadores da Saúde. Voto do Min. Relator, Marco Aurélio. Plenário. Brasília-DF, j. 11/04/2012i. Disponível em: <http:/www.stf.jus.br/arquivo/cms/ noticiaNoticiaStf/anexo/ADPF54.pdf>. Acesso em: 29 ago 2012. 
. Argüição de Descumprimento de Preceito Fundamental.

Anencefalia. Arguição de Descumprimento de Preceito Fundamental n. 54 ajuizada pela Confederação Nacional dos Trabalhadores da Saúde. Voto do Min. Ricardo Lewandowski. Plenário. Relator: Min. Marco Aurélio Mello. Brasília-DF, j. 11/04/2012j. Informativo do STF. Disponível em: $<$ http://s.conjur.com.br/dl/voto-lewandowski-fetoanencefalo.pdf $>$. Acesso em: 29 ago 2012.

DWORKIN, Ronald. "Objective and Truth: you'd better believed it" In: Philosophy and Public Affairs, Princeton, v. 25, n. 2, Princeton University Press, 1996.

. Levando os direitos a sério. São Paulo: Martins Fontes,

2002.

. Domínio da vida: aborto, eutanásia e liberdades individuais. São Paulo: Martins Fontes, 2003a.

. Império do direito. São Paulo: Martins Fontes, 2003b.

. Uma questão de princípio. São Paulo: Martins Fontes,

2005.

. Is democracy possible here? Principles for a New

Political Debate. Princeton: Princeton University Press, 2006.

. A justiça de toga. São Paulo: Martins Fontes, 2010.

. Justice for hedgehogs. Cambridge, Massachusetts:

Belknap Press of Harvard University, 2011.

FLEMING, James. Taking Responsabilities as Well as Rights Seriously. In: Boston University School of Law Symposium, Justice for Hedgehogs: a conference on Ronald Dworkin's Forthcoming Book, September, 2009. Disponível em: <http://www.bu.edu/law/central/jd/ organizations/journals/bulr/documents/FLEMING.pdf> . Acesso em: 29 ago 2012. 